\title{
The predictive power of the desmo-adhesome
}

\author{
Nicola Cirillo ${ }^{1}$, Stephen S. Prime ${ }^{2}$ \\ ${ }^{I}$ Melbourne Dental School \& Oral Health CRC, The University of Melbourne, Melbourne, VIC, \\ Australia \\ ${ }^{2}$ Centre for Clinical and Diagnostic Oral Sciences, Institute of Dentistry, Barts and the London School \\ of Medicine and Dentistry, Queen Mary University of London, UK
}

\section{*Address for Correspondence:}

Prof. Dr. Nicola Cirillo

Melbourne Dental School

The University of Melbourne

720 Swanston Street, Carlton

3053 Victoria, AUS

Tel/fax. +61039341 1597

e-mail: nicola.cirillo@unimelb.edu.au

\section{Comment on}

Rötzer V, Hartlieb E, Vielmuth F, Gliem M, Spindler V, Waschke J (2015) Ecadherin and Src associate with extradesmosomal Dsg3 and modulate desmosome assembly and adhesion. Cell Mol Life Sci 72(24):4885-4897 
Dear Sir,

In a recent report published in Cellular and Molecular Life Sciences, Jens Waschke's group provided further evidence of the cross talk between adherens junctions and desmosomes, with Src as a key molecule in this process [1]. We published in 2009 the first desmosomal interactome together with the directional interactions of its molecular consituents [2]. This allowed us to make predictions as to the role of specific proteins in desmosome dynamics as well as in response to perturbations. Prof. Waschke will recall that this "desmoadhesome" received mixed responses in the International Pemphigus meeting held in Bern in 2010, predominantly because it included proteins such as Src and $\beta$-catenin that were conventionally associated with adherens junctions but not desmosomes. More than six years later, a number of "unconventional" proteinprotein interactions have been demonstrated to be crucial for desmosome physiology, including those orchestrated by Src and $\beta$-catenin. In the manuscript recently published in this journal by Waschke's group [1], the authors show that Dsg3 forms a complex with E-cadherin and $\beta$-catenin and that this assembly is modulated by Src. In our seminal paper [2], the desmosomal interactome not only provided in silico evidence of the association between components of desmosomes and adherens junctions but also, it suggested that Src could phosphorylate both components in a junctional context.

One major result of our study was the experimentally verified prediction of a central role for Pkp3 in desmosome assembly and response to perturbation, as observed in the autoimmune disease Pemphigus Vulgaris (PV). Results of subsequent research published in this journal were consistent with a model where Pkp3 was crucial to desmosome formation and that this molecule was recruited to the cell border by plakoglobin (PG) and E-cadherin [3]. We now know that Pkp3 mediates both desmosome assembly and E-cadherin maturation [4] and that it is specifically targeted by PV autoimmunity [5].

In summary, the study by Rotzer et al. [1] further corroborates the hypothesis that an analysis of the desmosome at a systems level can facilitate the investigation of desmosome dynamics and provide a solid tool for an advance in the understanding of the pathogenesis of human skin disease. More broadly, the 
principles of complexity science, exemplified by the desmo-adhesome, can inform translational medicine and be of direct benefit to patients. Prospectively, it is not unlikely that computational biomedicine will lead to the discovery of robust and consistent markers of disease, as well as the identification of new genes responsible for genetic disease.

\section{References}

1] Rötzer V, Hartlieb E, Vielmuth F, Gliem M, Spindler V, Waschke J (2015) Ecadherin and Src associate with extradesmosomal Dsg3 and modulate desmosome assembly and adhesion. Cell Mol Life Sci 72:4885-4897

2] Cirillo N, Prime SS (2009) Desmosomal interactome in keratinocytes: a systems biology approach leading to an understanding of the pathogenesis of skin disease. Cell Mol Life Sci 66:3517-3533

3] Gosavi P, Kundu ST, Khapare N, Sehgal L, Karkhanis MS, Dalal SN (2011) Ecadherin and plakoglobin recruit plakophilin3 to the cell border to initiate desmosome assembly. Cell Mol Life Sci 68:1439-1454

4] Todorovic V, Koetsier JL, Godsel LM, Green KJ (2014) Plakophilin 3 mediates Rap1-dependent desmosome assembly and adherens junction maturation. Mol Biol Cell 25:3749-3764

5] Kalantari-Dehaghi M, Anhalt GJ, Camilleri MJ et al (2013) Pemphigus vulgaris autoantibody profiling by proteomic technique. PLoS One 8:e57587 


\section{University Library}

\section{- M M N E R VA A gateway to Melbourne's research publications}

Minerva Access is the Institutional Repository of The University of Melbourne

Author/s:

Cirillo, N;Prime, SS

Title:

The predictive power of the desmo-adhesome

Date:

2016-02-01

Citation:

Cirillo, N. \& Prime, S. S. (2016). The predictive power of the desmo-adhesome. CELLULAR AND MOLECULAR LIFE SCIENCES, 73 (3), pp.685-686. https://doi.org/10.1007/ s00018-015-2114-9.

Persistent Link:

http://hdl.handle.net/11343/282602 